\title{
Infectious Complications in Lupus Nephritis and Associated Factors: A Multicenter Study
}

\author{
Mansour Mbengue ${ }^{1}$, Myriam Mezouari $^{1}$, Seynabou Diagne ${ }^{2}$, Abdou Niang1 \\ ${ }^{1}$ Dalal Jamm Hospital, Dakar, Senegal \\ ${ }^{2}$ Pikine Hospital, Dakar, Senegal \\ Email: mansourmbengue92@gmail.com
}

How to cite this paper: Mbengue, M., Mezouari, M., Diagne, S. and Niang, A. (2021) Infectious Complications in Lupus Nephritis and Associated Factors: A Multicenter Study. Open Journal of Nephrology, 11, 506-515.

https://doi.org/10.4236/ojneph.2021.114043

Received: October 5, 2021

Accepted: December 27, 2021

Published: December 30, 2021

Copyright (c) 2021 by author(s) and Scientific Research Publishing Inc. This work is licensed under the Creative Commons Attribution International License (CC BY 4.0).

http://creativecommons.org/licenses/by/4.0/

\section{Open Access}

\begin{abstract}
Introduction: The prevalence of infections in patients with systemic lupus erythematosus ranges from $26 \%$ to $78 \%$. Patients with systemic lupus erythematosus are particularly susceptible to infections due to a dysfunction of immune response and the immunosuppressive therapy. Patients and method: We carried out this study with the aim of describing the prevalence of infections in lupus nephritis and determining the associated risk factors. This was a multicenter, observational, retrospective, descriptive and analytical study over a 10-year period from November 1, 2010 to October 31, 2020. The study was carried out in the nephrology departments of six hospitals in Dakar. Results: During the study period, 98 patients were included. The mean age was $32.32 \pm 11.33$ years with a sex ratio of 0.21 . Among the included patients, fifty-four (55.1\%) had at least one infectious episode, of which $53.7 \%$ had 1 infection, $24.1 \%$ had 2 infectious episodes and $22.2 \%$ had 3 infectious episodes. The overall incidence was 55.1 infections per 100 patient-years. $57.2 \%$ of these infectious episodes occurred within the first six months after the lupus was diagnosed. The main sites of infection were urinary (30.7\%), gastrointestinal $(22.0 \%)$ and pleuropulmonary (16.5\%). The incriminated germ was a bacterium in $78.18 \%$ of cases, a virus in $5.46 \%$, a parasite in 9.09 and a fungus in 7.27. The most frequently germ found was Escherichia coli (29.09\%). The evolution was marked by recovery in $93.4 \%$ of cases. Deaths occurred in 15 patients of which $33.3 \%$ were related to infections. Factor significantly associated with the onset of infection in multivariate analysis was the presence of a proliferative class of lupus nephritis $(p=0.013)$. Conclusion: Infections were common during lupus nephritis. The presence of a proliferative class was risk factors for infection.
\end{abstract}

\section{Keywords}

Lupus Nephritis, Infection, Proliferative Class 


\section{Introduction}

The prevalence of infections in systemic lupus erythematosus (SLE) patients ranges from $26 \%$ to $78 \%$ [1] [2] [3]. Patients with SLE are particularly susceptible to infections due to a dysfunction of the innate and adaptive immune response associated with the disease, which is exacerbated by the immunosuppressive therapy used to treat the disease [4]. This explains the higher infectious risk of patients with SLE compared to the general population [5]. Infections are one of the main causes of morbidity and mortality during SLE, especially in case of lupus nephritis (LN). They are responsible for $15 \%$ to $40 \%$ of patient admissions and $30 \%$ to $50 \%$ of deaths [3] [6] [7]. The prevalence of infections in LN is not sufficiently described in sub-Saharan Africa. We carried out this study with the aim of describing the prevalence of infections in LN and determining the associated risk factors.

\section{Patients and Methods}

This was a multicenter, observational, retrospective, descriptive and analytical study over a 10-year period from November 1, 2010 to October 31, 2020. The study was carried out in the nephrology departments of 6 hospitals in Dakar (Aristide Le DANTEC hospital, Dalal Jamm hospital, Pikine hospital, Principal hospital, Ouakam military hospital, Roi Baudoin hospital). The study included all records of patients who were followed for LN. The diagnosis of LN was made by a concordant renal biopsy associated with a proteinuria/creatinuria ratio greater than $0.5 \mathrm{~g} / \mathrm{g}$ or with an active urine sediment [8]. For each selected patient, the epidemiological, clinical, biological, histological, therapeutic and evolutionary data were studied. The data collected were entered from Excel software. The descriptive study was carried out with the calculation of the means \pm standard deviation [minimum, maximum] or medians for the quantitative variables and the calculation of the frequencies for the qualitative variables. Data analysis was performed using SPSS software (Statistical Package for Science Social) version 18. The means and percentages were compared using the chi-square test and the exact Fischer test, respectively, according to their conditions of applicability. Any difference less than 0.05 was considered statistically significant. For multivariate analysis, we used a binary logistic regression model and included in this model the variables that were significant in bivariate analysis. The significance level retained for all the statistical analyzes was at $\mathrm{p} \leq 0.05$.

\section{Results}

Ninety-eight patients were included. The mean age was $32.32 \pm 11.33$ years with a female predominance and a sex ratio of 0.21 . The average duration of follow-up was $25.40 \pm 20.40$ months. Forty-eight patients were known to have lupus prior to renal impairment. The mean glomerular filtration rate (GFR) was $89.88 \mathrm{ml} / \mathrm{min} \pm 53.65$ and $27.6 \%$ of patients had renal failure. C-reactive protein was measured in 68 patients, it was positive in 27 patients (39.7\%). The mean 
serum albumin was $21.25 \pm 9.67 \mathrm{mg} / \mathrm{L}$. The mean protidemia was $54.03 \pm 11.87$ $\mathrm{mg} / \mathrm{l}$. The mean proteinuria was $4.11 \mathrm{~g} / 24 \mathrm{~h} \pm 3.40$. Nephrotic syndrome was found in $58.2 \%$ of cases. Isolated class $\mathrm{V}$ was the most common, found in 34 cases $(34.7 \%)$, class III $+\mathrm{V}$ in 24 cases $(24.5 \%)$, class IV in 11 cases $(11.2 \%)$ and class IV $+\mathrm{V}$ in 10 cases $(10.2 \%)$, class II was found in 9 cases $(9.2 \%)$, class III in 6 cases $(6.1 \%)$ and class I in 4 cases (4.1\%). Hydroxychloroquine (HCQ) was prescribed in $83.7 \%$ of patients, methylprednisolone (MTP) in $59.2 \%$ of patients, prednisone was prescribed in $95.9 \%$ of patients, cyclophosphamide (CYC) in $27.6 \%$ of patients; mycophenolate mofetil (MMF) in $38.8 \%$ of patients and azathioprine (AZA) in $27.6 \%$ of patients (Table 1). Eighty-eleven infectious episodes have been identified. Fifty-four patients $(55.1 \%)$ had at least one infectious episode, of which $53.7 \%$ had 1 infection, $24.1 \%$ had 2 infectious episodes and $22.2 \%$ had 3 infectious episodes. The overall incidence was 55.1 infections per 100 patient-years. The median time to onset of infection was 8.90 months \pm $13.13 \%$ and $57.2 \%$ of these episodes occurred within the first six months after the lupus was diagnosed. The main sites of infection were urinary (30.7\%), gastrointestinal (22.0\%), pleuropulmonary (16.5\%) and skin (13.2\%) (Figure 1). The germ was identified in $60.43 \%$ of cases and it was a bacterium in $78.18 \%$ of cases. The most frequently found germs were Escherichia coli (29.09\%) and Staphylococcus aureus (14.55\%) (Table 2). Hospitalization was necessary in $27.5 \%$ of infectious episodes. The evolution was marked by recovery in $93.4 \%$ of cases. Deaths occurred in 15 patients (15.3\%) of which 5 (33.3\%) were related to infections. In bivariate analysis, the factors significantly associated with the onset of infection were elevated serum creatinine level on admission $(\mathrm{p}=0.027)$, renal failure $(\mathrm{p}=0.005)$, proliferative class of LN ( $\mathrm{p}=0.001)$, taking MTP $(\mathrm{p}=0.001)$ and oral corticosteroid therapy $(\mathrm{p}=0.038)$ (Table 3 ). Factors significantly associated with the onset of infection in multivariate analysis was the presence of a proliferative class of $\mathrm{LN}(\mathrm{p}=0.013)$ (Table 4).

\section{Discussion}

The prevalence of infections varies across studies. In our series, $55.1 \%$ of patients presented at least with one infectious episode. These results are similar to those of Ibn Abdelouahab [9] and Yin et al. [10] which were 61.6\% and 49.3\% respectively. In Australia, in the series by Feldman et al. [1], the prevalence was lower (25.7\%) (Table 5). This difference is explained by the fact that Feldman et al only considered severe infections. Infections can affect one or more organs at the same time. They affect the lung, skin and urinary tract in more than two thirds of cases [11] [12]. In our study, these three locations represented $60 \%$ of cases. The other locations (osteoarticular, central nervous system, endocardium...) were rare. Lupus itself predisposes to infectious complications. Indeed, some intrinsic factors are involved in this immunosuppression: decrease in chemotaxis and phagocytosis; functional asplenia [13]; hypocomplementemia by excessive consumption of the $\mathrm{C} 3$ and $\mathrm{C} 4$ fractions of the complement or congenital deficit 
Table 1. Demographical and clinical characteristics of participants.

\begin{tabular}{|c|c|}
\hline Variables & Effectives \\
\hline Mean age (years) & $32.32 \pm 11.33$ \\
\hline \multicolumn{2}{|l|}{ Age groups (years) } \\
\hline$<20$ & $8(8.2 \%)$ \\
\hline $20-40$ & $60(61.2 \%)$ \\
\hline $40-60$ & $28(28.6 \%)$ \\
\hline$>60$ & $2(2 \%)$ \\
\hline \multicolumn{2}{|l|}{ Gender (\%) } \\
\hline Men & $81(82.7 \%)$ \\
\hline Women & $17(17.3 \%)$ \\
\hline Protidemia (g/l) & $54.03 \pm 11.87$ \\
\hline Albuminemia (g/l) & $1.25 \pm 9.67$ \\
\hline Azotemia (g/l) & $0.62 \pm 0.79$ \\
\hline Serum creatinine $(\mathrm{mg} / \mathrm{l})$ & $17.71 \pm 23.77$ \\
\hline GFR $\left(\mathrm{ml} / \mathrm{min} / 1.73 \mathrm{~m}^{2}\right)$ & $89.88 \pm 53.65$ \\
\hline Renal failure (\%) & $27(27.6 \%)$ \\
\hline Hematuria (\%) & $35(35.7 \%)$ \\
\hline Proteinuria (g/24h) & $4.11 \pm 3.4$ \\
\hline Nephrotic syndrome (\%) & $57(58.2 \%)$ \\
\hline C3 hypocomplementemia (\%) & $5(5.1 \%)$ \\
\hline C4 hypocomplementemia (\%) & $6(6.1 \%)$ \\
\hline CH50 hypocomplementemia (\%) & $2(2 \%)$ \\
\hline Anti-DNA antibodies (\%) & $33(33.6 \%)$ \\
\hline ANA (\%) & $51(52 \%)$ \\
\hline Anti-Sm antibodies & $24(24.48 \%)$ \\
\hline \multicolumn{2}{|l|}{ Classes (\%) } \\
\hline I & $4(4.1 \%)$ \\
\hline II & $9(9.2 \%)$ \\
\hline III & $6(6.1 \%)$ \\
\hline $\mathrm{III}+\mathrm{V}$ & $11(11.2 \%)$ \\
\hline IV & $24(24.5 \%)$ \\
\hline $\mathrm{IV}+\mathrm{V}$ & $10(10.2 \%)$ \\
\hline $\mathrm{V}$ & $34(34.7 \%)$ \\
\hline VI & $0(0 \%)$ \\
\hline \multicolumn{2}{|l|}{ Immunosuppressants (\%) } \\
\hline Corticosteroids & $94(95.9 \%)$ \\
\hline CYC & $27(27.6 \%)$ \\
\hline MMF & $38(38.8 \%)$ \\
\hline AZA & $27(27.6 \%)$ \\
\hline RTX & $1(1 \%)$ \\
\hline Cyclosporine & $2(2 \%)$ \\
\hline
\end{tabular}

GFR $=$ glomerular filtration rate, ANA $=$ anti-n556.uclear antibodies, anti-Sm $=$ Anti-Smith antibodies CYC = cyclophosphamide, $\mathrm{MMF}=$ mycophenolate mofetil, AZA = Azathioprine, RTX = rituximab. 


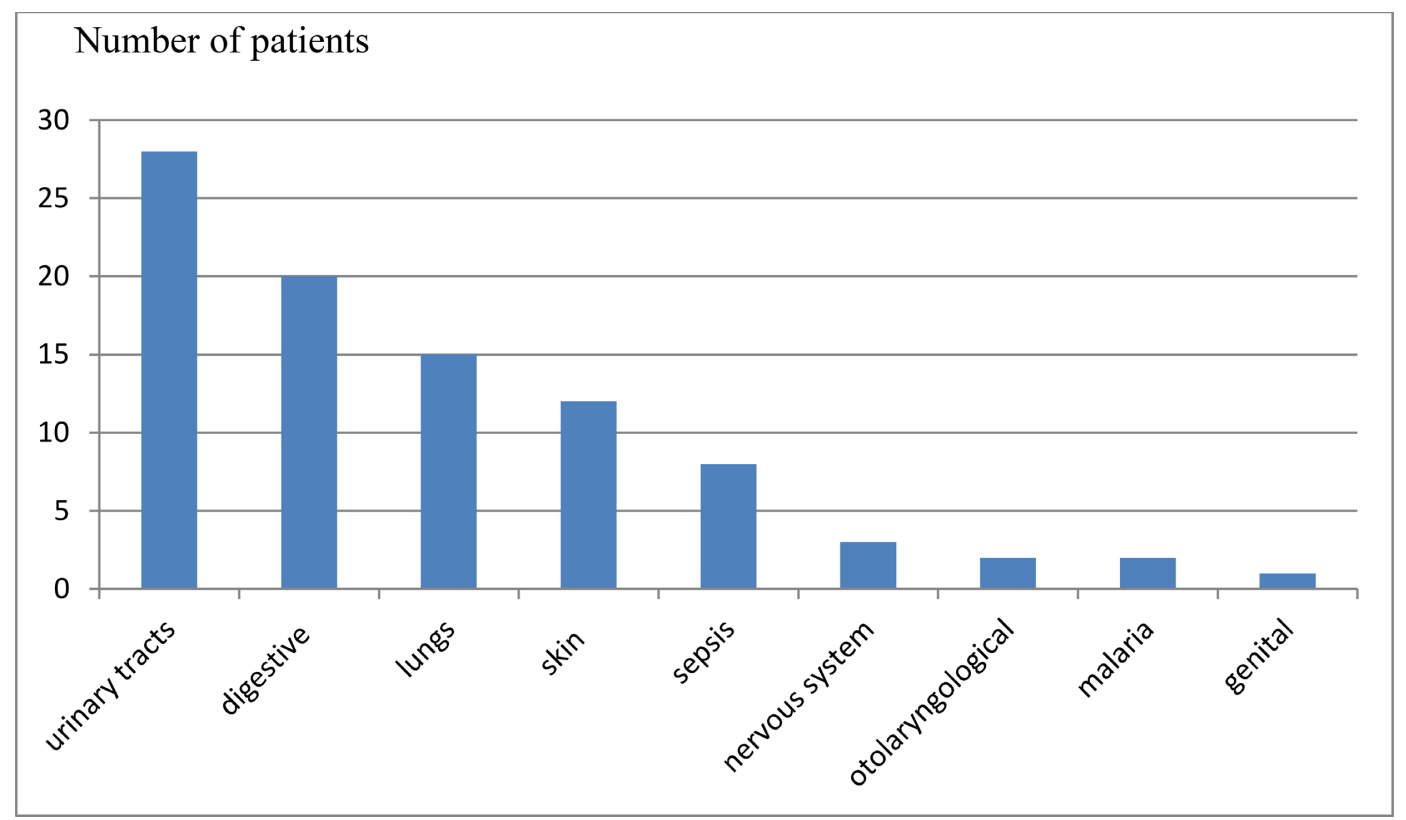

Figure 1. Distribution of patients according to the infectious site.

Table 2. Distribution of documented infections according to germs.

\begin{tabular}{|c|c|c|c|}
\hline & Germs & Effectives & Percentages \\
\hline \multirow[t]{11}{*}{ Bacteria } & Escherichia coli & 16 & 29.09 \\
\hline & Staphylococcus aureus & 8 & 14.55 \\
\hline & Enterobacter spp & 5 & 9.09 \\
\hline & Klebsiella pneumoniae & 3 & 5.45 \\
\hline & Mycobacterium tuberculosis & 3 & 5.45 \\
\hline & Streptococcus pneumoniae & 2 & 3.64 \\
\hline & Meningococcus & 2 & 3.64 \\
\hline & Citrobacter freundii & 1 & 1.82 \\
\hline & beta-hemolytic Streptococcus & 1 & 1.82 \\
\hline & Klebsiella pneumoniae & 1 & 1.82 \\
\hline & Gardenerella vaginalis & 1 & 1.82 \\
\hline \multirow[t]{3}{*}{ Viruses } & Herpes zoster & 1 & 1.82 \\
\hline & varicella-zoster virus & 1 & 1.82 \\
\hline & Hepatitis $B$ virus & 1 & 1.82 \\
\hline \multirow[t]{4}{*}{ Parasites } & Plasmodium falciparum & 2 & 3.64 \\
\hline & sarcoptes scabiei & 1 & 1.82 \\
\hline & Trichomonas vaginalis & 1 & 1.82 \\
\hline & Entamoeba histolytica & 1 & 1.82 \\
\hline Fungus & Candida albicans & 4 & 7.27 \\
\hline Total & & 55 & $100 \%$ \\
\hline
\end{tabular}


Table 3. Bivariate analysis of risk factors for infection.

\begin{tabular}{|c|c|c|c|}
\hline Variables & Infection $(n=54)$ & No infection $(n=44)$ & $\mathrm{p}$ \\
\hline \multicolumn{4}{|l|}{ Gender (\%) } \\
\hline Women & $45(83.3 \%)$ & $36(81.8 \%)$ & \multirow{2}{*}{0.844} \\
\hline Men & $9(16.7 \%)$ & $8(18.2 \%)$ & \\
\hline \multicolumn{4}{|l|}{ Age groups (years) } \\
\hline$<20$ & $5(9.3 \%)$ & $3(6.8 \%)$ & \multirow{4}{*}{0.365} \\
\hline $20-40$ & $35(64.8 \%)$ & $25(56.8 \%)$ & \\
\hline $41-60$ & $14(25.9 \%)$ & $14(31.8 \%)$ & \\
\hline$>60$ & $0(0 \%)$ & $2(4.5 \%)$ & \\
\hline Duration of follow-up (months) & $28.72 \pm 20.53$ & $21.32 \pm 19.70$ & 0.074 \\
\hline Serum creatinine (mg/l) & $22.55 \pm 29.78$ & $11.88 \pm 11.20$ & 0.027 \\
\hline Renal failure (\%) & $21(38.9 \%)$ & $6(13.6 \%)$ & 0.005 \\
\hline Nephrotic syndrome (\%) & $35(64.8 \%)$ & $22(50.0 \%)$ & 0.139 \\
\hline Leucopenia (\%) & $4(7.4 \%)$ & $6(13.6 \%)$ & 0.248 \\
\hline Lymphopenia (\%) & $21(38.9 \%)$ & $19(43.2 \%)$ & 0.667 \\
\hline ANA (\%) & $27(93.1 \%)$ & $24(92.3 \%)$ & 0.652 \\
\hline Anti-DNA antibodies (\%) & $16(64.0 \%)$ & $17(68.0 \%)$ & 0.765 \\
\hline C3 hypocomplementemia (\%) & $4(57.1 \%)$ & $1(14.3 \%)$ & 0.133 \\
\hline C4 hypocomplementemia (\%) & $4(57.1 \%)$ & $2(28.6 \%)$ & 0.296 \\
\hline Proliferatives classes (\%) & $37(68.5 \%)$ & $14(31.8 \%)$ & 0.001 \\
\hline HCQ (\%) & $44(81.5 \%)$ & $38(86.4 \%)$ & 0.515 \\
\hline MTP (\%) & $40(74.1 \%)$ & $18(40.9 \%)$ & 0.001 \\
\hline Prednisone (\%) & $54(100.0 \%)$ & $40(90.9 \%)$ & 0.038 \\
\hline MMF (\%) & $25(46.3 \%)$ & $13(29.5 \%)$ & 0.090 \\
\hline CYC (\%) & $19(35.2 \%)$ & $8(18.2 \%)$ & 0.061 \\
\hline AZA (\%) & $19(35.2 \%)$ & $8(18.2 \%)$ & 0.061 \\
\hline
\end{tabular}

ANA = anti-nuclear antibodies, HCQ = hydroxychloroquine, MTP = methylprednisolone, $\mathrm{CYC}=$ cyclophosphamide, $\mathrm{MMF}=$ mycophenolate mofetil, $\mathrm{AZA}=$ Azathioprine, $\mathrm{RTX}=$ rituximab.

Table 4. Multivariate regression analysis of factors associated with infection.

\begin{tabular}{cccccc}
\hline Variables & $\begin{array}{c}\text { Infection } \\
(\mathbf{n}=54)\end{array}$ & $\begin{array}{c}\text { No infection } \\
(\mathbf{n}=44)\end{array}$ & OR & IC & p \\
\hline Serum creatinine (mg/l) & $22.55 \pm 29.78$ & $11.88 \pm 11.20$ & & NS \\
Renal failure (\%) & $21(38.9 \%)$ & $6(13.6 \%)$ & & & NS \\
Proliferatives classes (\%) & $37(68.5 \%)$ & $14(31.8 \%)$ & 3.598 & $1.85-9.56$ & 0.013 \\
MTP (\%) & $40(74.1 \%)$ & $18(40.9 \%)$ & & & NS \\
Prednisone (\%) & $54(100.0 \%)$ & $40(90.9 \%)$ & & & NS \\
\hline
\end{tabular}

MTP = methylprednisolone; NS = not significant; OR = odds ratio; IC = interval of confidence. 
Table 5. Incidence of infections reported by other studies.

\begin{tabular}{ccc}
\hline Authors & Countries & Incidence of infections (100 patient-years) \\
\hline Liu [21] & Singapore & 17.6 \\
Feldman [8] & United states & 23.9 \\
Mon [24] & Australia & 18.4 \\
Ibn Abdelouahab [9] & Morocco & 35.5 \\
Our series & Senegal & 55.1 \\
\hline
\end{tabular}

in certain fractions of the complement (C1r, C1s, C3 and C4) [14] [15]; polymorphism of MBL and ostepontin [11] [16] [17]; increased levels of Fc gamma III and GM-CSF levels [16], decreased cytotoxic activity of T lymphocytes (CD8) and the production of several factors having a major anti-infectious role (interleukins 1 and 2, interferons) [11].

Renal involvement also exposes to infectious complications due to immunosuppression caused by chronic renal failure and hypogammaglobulinemia in nephrotic syndrome. Other elements are frequently associated with the onset of infectious episodes. These are lymphopenia [18] and the use of immunosuppressive treatments (corticosteroids, azathioprine, cyclophosphamide, etc.) [14] [19] [20]. In our series, infections occurred in $57.1 \%$ of cases during the first six months of follow-up, coinciding with the period of induction therapy. These results agree with those of other studies in China (57.8\%) [10] and Morocco (72.9\%) [9]. The high prevalence during that period is explained by the fact that firstly the disease is more active during that period and secondly the immunosuppressive treatment is more intense during that period because it corresponds to the induction treatment. In our series, death occurred in $15.3 \%$ of cases, of which $33.3 \%$ of deaths were related to infectious causes.

This rate matches the one found in the series by Liu et al. [21] and Béji et al. [22] where infection was responsible for $43 \%$ and $38.8 \%$ of deaths, respectively. In the series by Ibn Abdelouahab [9] and Yap et al. [23], infectious complications were responsible for $66.6 \%$ and $50.5 \%$ of deaths, respectively, which is to be expected, since infections are one of the leading causes of death in LN. The proliferative class of LN was significantly associated with the onset of infection.

In a Moroccan study, Ibn Abdelouahab found that patients with proliferative LN had a significantly higher infection rate compared to patients with non proliferative LN [9]. This risk is explained by the fact that on one hand the proliferative classes are more severe and more active and on the other hand they require more intense immunosuppressive treatment than the non proliferative classes.

\section{Conclusion}

Infections were common during LN. The presence of a proliferative class was risk factors for infection. 


\section{Funding Sources}

This research did not receive a specific grant from any funding agency in the public, commercial, or not-for-profit sectors.

\section{Author Contributions}

Mansour Mbengue reviewed the literature and wrote the first draft of the manuscript. All authors reviewed and edited the manuscript and approved the final version of the manuscript.

\section{Limitations}

The retrospective design of our study represents a limitation.

\section{Conflicts of Interest}

The authors declare no conflicts of interest regarding the publication of this paper.

\section{References}

[1] Feldman, C.H., Hiraki, L.T., Winkelmayer, W.C., Marty, F.M., Franklin, J.M., Kim, S.C., et al. (2015) Serious Infections among Adult Medicaid Beneficiaries with Systemic Lupus Erythematosus and Lupus Nephritis. Arthritis \& Rheumatology, 67, 1577-1585. https://doi.org/10.1002/art.39070

[2] Jallouli, M., Frigui, M., Marzouka, S., Maaloul, I., Kaddour, N. and Bahloul, Z. (2008) Infectious Complications in Systemic Lupus Erythematosus: A Series of 146 Patients. La Revue de Médecine Interne, 29, 626-631. https://doi.org/10.1016/j.revmed.2008.02.023

[3] Yap, D.Y.H., Tang, C.S.O., Ma, M.K.M., Lam, M.F. and Chan, T.M. (2012) Survival Analysis and Causes of Mortality in Patients with Lupus Nephritis. Nephrology Dialysis Transplantation, 27, 3248-3254. https://doi.org/10.1093/ndt/gfs073

[4] Ren, Y., Tang, J., Mok, M.Y., Chan, A.W., Wu, A. and Lau, C.S. (2003) Increased Apoptotic Neutrophils and Macrophages and Impaired Macrophage Phagocytic Clearance of Apoptotic Neutrophils in Systemic Lupus Erythematosus. Arthritis \& Rheumatology, 48, 2888-2897. https://doi.org/10.1002/art.11237

[5] Herrinton, L.J., Liu, L., Goldfien, R., Alex Michaels, M. and Tran, T.N. (2016) Risk of Serious Infection for Patients with Systemic Lupus Erythematosus Starting Glucocorticoids with or without Antimalarials. The Journal of Rheumatology, 43, 1503-1509. https://doi.org/10.3899/jrheum.150671

[6] Yee, C.S., Su, L., Toescu, V., Hickman, R., Situnayake, D., Bowman, S., et al. (2015) Birmingham SLE Cohort: Outcomes of a Large Inception Cohort Followed for up to 21 Years. Rheumatology, 54, 836-843. https://doi.org/10.1093/rheumatology/keu412

[7] Lim, C.C., Liu, P.Y., Tan, H.Z., Lee, P., Chin, Y.M., Mok, I.Y.J., et al. (2017) Severe Infections in Patients with Lupus Nephritis Treated with Immunosuppressants: A Retrospective Cohort Study. Nephrology, 22, 478-484. https://doi.org/10.1111/nep.12809

[8] Houssiau, F.A., Vasconcelos, C., D'Cruz, D., et al. (2010) The 10-Year Follow-Up Data of the Euro-Lupus Nephritis Trial Comparing Low-Dose and High-Dose Intravenous Cyclophosphamide. Annals of the Rheumatic Diseases, 69, 61-64. 
https://doi.org/10.1136/ard.2008.102533

[9] Ibn Abdelouahab, A. (2020) Epidémiologie et facteurs de risque des infections au cours de la néphropathie lupique. Thèse de médecine. Université Mohammed V de Rabat, Rabat.

[10] Yin, P., Li, J., Wen, Q., Qiu, Y., Liang, W., Wang, J., et al. (2020) Infection-Related Hospitalization after Intensive Immunosuppressive Therapy among Lupus Nephritis and ANCA Glomerulonephritis Patients. Renal Failure, 42, 474-482. https://doi.org/10.1080/0886022X.2020.1763400

[11] Barri, J. and Fessler, M.D. (2002) Infectious Diseases in Systemic Lupus Erythematosus: Risk Factors, Management and Prophylaxis. Best Practice \& Research: Clinical Rheumatology, 16, 281-291. https://doi.org/10.1053/berh.2001.0226

[12] Bertsias, G.K., Tektonidou, M., Amoura, Z., Aringer, M., Bajema, I., Berden, J.H., et al. (2012) Joint European League against Rheumatism and European Renal Association European Dialysis and Transplant Association (EULAR/ERA-EDTA) Recommendations for the Management of Adult and Paediatric Lupus Nephritis. Annals of the Rheumatic Diseases, 71, 1771-1782.

https://doi.org/10.1136/annrheumdis-2012-201940

[13] Neilan, B.A. and Berney, S.N. (1983) Hyposplenism in Systemic Lupus Erythematosus. The Journal of Rheumatology, 10, 332-334.

[14] Bosch, X., Guilabert, A., Pallarés, L., Cervera, R., Ramos-Casals, M., Bové, A., et al. (2006) Infections in Systemic Lupus Erythematosus: A Prospective and Controlled Study of 110 Patients. Lupus, 15, 584-589.

https://doi.org/10.1177/0961203306071919

[15] Kang, I. and Park, S.H. (2003) Infectious Complications in SLE after Immunosuppressive Therapies. Current Opinion in Rheumatology, 15, 528-534. https://doi.org/10.1097/00002281-200309000-00002

[16] Falagas, M.E., Manta, K.G., Betsi, G.I. and Pappas, G. (2007) Infection-Related Morbidity and Mortality in Patients with Connective Tissue Diseases: A Systematic Review. Clinical Rheumatology, 26, 663-670. https://doi.org/10.1007/s10067-006-0441-9

[17] Zandman-Goddard, G. and Shoenfield, Y. (2005) Infections and SLE. Autoimmunity, 38, 473-485.

[18] Houssiau, F.A., Vasconcelos, C., D’Cruz, D., Sebastiani, G.D., De Ramon Garrido, E., Danieli, M.G., et al. (2004) Early Response to Immunosuppressive Therapy Predicts Good Renal Outcome in Lupus Nephritis: Lessons from Long-Term Follow-Up of Patients in the Euro-Lupus Nephritis Trial. Arthritis \& Rheumatology, 50, 3934-3940. https://doi.org/10.1002/art.20666

[19] Gladman, D.D., Hussain, F., Ibanez, D. and Urowitz, M.B. (2002) The Nature and Outcome of Infection in Systemic Lupus Erythematosus. Lupus, 11, 234-239. https://doi.org/10.1191/0961203302lu170oa

[20] Zonana-Nacach, A., Camargo-Coronel, A., Yanez, P., Sanchez, L., Jimenez-Balderas, F.J. and Fraga, A. (2001) Infections in Outpatients with Systemic Lupus Erythematosus: A Prospective Study. Lupus, 10, 505-510. https://doi.org/10.1191/096120301678416088

[21] Liu, P., Tan, H.Z., Li, H., Lim, C.C. and Choo, J.C.J. (2018) Infections in Hospitalized Lupus Nephritis Patients: Characteristics, Risk Factors, and Outcomes. Lupus, 27, 1150-1158. https://doi.org/10.1177/0961203318768881

[22] Van Tellingen, A., Voskuyl, A.E., Vervloet, M.G., et al. (2012) Dutch Guidelines for 
Diagnosis and Therapy of Proliferative Lupus Nephritis. The Netherlands Journal of Medicine, 70, 199-207.

[23] Wang, B., Gladman, D.D. and Urowitz, M.B. (1998) Fatigue in Lupus Is Not Correlated with Disease Activity. The Journal of Rheumatology, 25, 892-895.

[24] Mon, S.Y., Yates, D., Kubler, P., Manickam, V., Muriel, S., Oh, Y., et al. (2019) Increased Risk of Infection in SLE: Renal Involvement or Steroid Dosage? Kidney International, 4, S165-S166. https://doi.org/10.1016/j.ekir.2019.05.427 